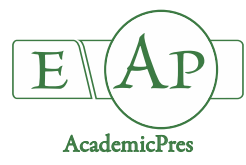

\title{
Biocontrol of Pear Postharvest Decay by Kombucha
}

\author{
Junping $\mathrm{TAN}^{1}$, Xian $\mathrm{ZHOU}^{1}$, Shuiyuan $\mathrm{CHENG}^{2}$, Zexiong $\mathrm{CHEN}^{3}$, \\ Yuanyuan $\mathrm{GOU}^{1}$, Jiabao $\mathrm{YE}^{1}$, Feng $\mathrm{XU}^{1 *}$ \\ ${ }^{1}$ Yangtze University, College of Horticulture and Gardening, Jingzhou 434025, Hubei, China; tanjunping0318@163.com; \\ chenxitianmu@126.com; gouyuanyuan0307@163.com;yejiabao13@163.com;xufeng198@126.com(*corresponding author) \\ ${ }^{2}$ Wuhan Polytechnic University, National R\&D for Se-rich Agricultural Products Processing Technology, Wuhan, 430023, \\ China;s_y_cheng@sina.com \\ ${ }^{3}$ Chongqing University of Arts and Sciences, Research Institute for Special Plants, Yongchuan 402160, Chongqing, \\ China; chenzexiong1979@163.com
}

\begin{abstract}
Kombucha is sweetened, slightly alcoholic, and lightly effervescent tea drink. Its acidity inhibits the growth of harmful bacteria. Here, we studied effect of kombucha on post-harvest preservation of pear. The Hosui pears were soaked with the kombucha for 15 minutes, and in distilled water as the control, respectively. Superoxide dismutase (SOD), peroxidase (POD), malondialdehyde (MDA), hydrogen peroxide $\left(\mathrm{H}_{2} \mathrm{O}_{2}\right)$, proline content, electric conductivity, weight loss rate and good fruit rate in pear were measured during storage at room temperature. The results showed that the kombucha could effectively prolong the storage time of pear fruit. The fruit quality of the treated group was 1.5 times higher than that of the control pear fruit when stored at room temperature for 18 days. The weight loss rate, MDA content and electric conductivity of the treatment group were lower than those of the control group during the whole storage period, indicating that kombucha can inhibit the transformation of polysaccharides such as starch and pectin, and delay the degradation of nutrients in the fruit, resulting in a decrease in weight loss rate, inhibition of membrane lipid peroxidation, reducing MDA content, electric conductivity, maintaining cell membrane stability, delaying pear fruit senescence. Kombucha can inhibit the content of $\mathrm{H}_{2} \mathrm{O}_{2}$ and proline, increase the activity of POD and SOD increase the storage stability of fruits. The purpose of this study was to elucidate the physiological mechanism of post-harvest preservation of pear by kombucha. The use of kombucha can prolong the supply period of pear, increase economic benefits and expand the market of pear.
\end{abstract}

Keywords: antioxidant enzyme activity; electric conductivity; fruit storability; kombucha; pear; proline

\section{Introduction}

Pyrus pyrifolia is a deciduous fruit tree of the Rosaceae. Pear was one of the five major fruits of China, and the various resources are very rich. China was also one of the origins of pear, and there was distribution and cultivation of pear trees throughout the country (Huang et al., 2009). Pear fruit was crispy, fine pulp, low sclereid content, high juice content, excellent flavor, soluble solid content as high as 8$15 \%$, aroma, and high quality (Itai and Tanahashi, 2008). Pear has strong disease resistance and develops rapidly. Its fruit yield increases yearly, but it has poor storage capacity. Under normal temperature conditions, its disease resistance decreases after its fruits are harvested, and mechanical damage occurs during storage and transport. Pathogenic microbial breeding and growth in fields and infection in fruits cause decay and commodity loss, resulting in fruit wastage and economic losses (Huang et al., 2009). Pear ripening season occurs in summer in a high-temperature zone with a short harvest period and easy to cause sales concentration. Pears are respiratory climacteric fruits with strong metabolism. They are prone to respiratory peak after harvest, thereby accelerating senescence, leading to a decline in quality of pears and an increase in rot rate, and resulting in a decrease in shelf life (Fan et al., 2016). Therefore, studies on the post-harvest preservation technology of pears can play an important role in extending the delivery period, reducing fruit loss, increasing economic benefits, and increasing market share.

With continuous advancements in pear storage and preservation technology, fresh-keeping materials, including plastic wrapes, preservatives, and fresh-keeping packaging, have been continuously developed. With the development of society, customers have focused on problems associated 
with chemical residues in fruits and vegetables. As such, the use of pollution-free fresh-keeping methods of pear preservation had been extensively investigated. The main methods of storing and preserving pears include gas absorption, heat treatment, preservative coating, 1-MCP treatment, and biological preservation. Preservative coating was low cost and had a good anti-corrosion effect, but it produces a large chemical reagent residue and harms the human body, possibly causing cancer, teratogenicity, and mutagenicity in serious cases (Groppa and Benavides, 2008; Moon et al., 2008; Li et al., 2013; Liu et al., 2013). Biological preservatives are extracted from animals, plants, and microorganisms and applied to preserve fruits through immersion, coating, and other methods (Sharma et al., 2009; Aziz and Karboune, 2018). The preservation mechanism involves the use of active antibacterial substances to kill spoilage bacteria in fruits, inhibiting enzyme activities to form a protective film and preventing microbial infection (Pareek et al., 2011). The types of biological preservatives can be classified into plant, animal, microbial, and biological enzyme preservatives based on their different sources. Holmes et al. (2008) found that plant-based biological preservatives include hydrocinnamyl compounds, such as flavonoids, flavonols, coumarins, chromones, and alkaloids, and they have a good inhibitory function of Aspergillus flavus, which can promote fruit storage and preservation time. The most prevalent animal preservatives are chitosan, propolis, and collagen, which generally have sterilization, antisepsis, and other functions. In microbial preservation technology, microbial cells are used to treat bacteria. Zahvai et al. (2000) studied the inhibitory effect of Candida guilliermondii on rot caused by Botrytis cinerea and Aspergillus niger, and found that treatment with yeast can reduce the loss of decay by $16.81 \%$ and $60 \%$, respectively. Kombucha, as one of the microbial cells, was a substance beneficial to the human body and produced by sugar fermentation, tea, and water. Its acidity can inhibit the growth of harmful bacteria and benefit human health (Dufresne and Farnworth, 2000). Kombucha had a good effect on the treatment of atrophic gastritis, gastric ulcer, and other serious diseases (Abshenas et al., 2012). It can also regulate blood pressure, improve sleep, prevent, and treat various diseases (Mayser et al., 1995; Dufresne and Farnworth, 2000). Greenwalt et al. (1998) and Sreeramulu et al. (2001) demonstrated that kombucha fermentation broth strongly inhibits some common pathogenic Gram-positive and Gram-negative bacteria and common food spoilage bacteria. Bacterial analysis had revealed that kombucha was mainly a commensal of yeast, lactic acid bacteria, and acetic acid bacteria. Many reports on yeast have been presented. For example, Yan et al. (2014) studied the prevention and control of Rhodotorula glutinis in combination with rhamnolipids and found that the combination of $R$. glutinis with rhamnolipid can significantly enhance the activities of peroxidase, polyphenol oxidase, and phenylalanine ammonia-lyase in cherry tomatoes. Lu et al. (2014) investigated the antagonistic effect of chitin combined with Marine red yeast on Penicillium extended to apple fruit and observed that chitin can increase the activity of polyphenol oxidase and superoxide dismutase in apples. Microbial preservation technology is safe, nontoxic, and nonpolluting and had been widely explored for the storage and preservation of fruits and vegetables. However, the application of the storage and preservation of kombucha on fruits and vegetables had not yet to be reported. To further study the application of kombucha in fruit post-harvest preservation, we used kombucha to treat post-harvest pear fruits, and its effect was reflected by determining the activities of superoxide dismutase (SOD), peroxidase (POD), malondialdehyde (MDA), hydrogen peroxide $\left(\mathrm{H}_{2} \mathrm{O}_{2}\right)$, and proline contents, electric conductivity, fruit weight loss rate, and good fruit rate. This study provided a theoretical and practical basis for the storage and preservation of pear fruit.

\section{Materials and Methods}

\section{Preparation ofkombucha}

Kombucha was preserved in the laboratory. Preparation of kombucha fermentation broth: $1 \mathrm{~g}$ of tea, $10 \mathrm{~g}$ of sucrose and $2 \mathrm{~g}$ of kombucha species are added per $100 \mathrm{~mL}$ of distilled water. The black tea was boiled in distilled water for $20 \mathrm{~min}$, sucrose was added, and the whole solution was stirred. After cooling to $25^{\circ} \mathrm{C}$, the strain of kombucha was inoculated, shaken, sealed with 6 layers of gauze, and transferred to $30{ }^{\circ} \mathrm{C}$ electric heating incubator for fermentation. The fermentation broth was fermented for 2 weeks, and the kombucha membrane and other large impurities was removed by filtration, and the filtrate was the kombucha.

\section{Materials and treatment}

Pear samples (Pyrus pyrifolia Nakai cv. 'Hosui') was harvested from the pear germplasm resources of the deciduous fruit tree base of Yangtze University. Hosui was a pear native of Japan and belongs to early maturing cultivar. Fruit of visible damage or decay and with similar size were selected. Then the pears were randomly divided into two groups of 36 fruits each. According to the preliminary test in the previous period, it was selected to be immersed in distilled water for $15 \mathrm{~min}$ as the control group (water), the kombucha tea was immersed in kombucha tea for $15 \mathrm{~min}$ for the treatment group. The treated pear fruits were stored at room temperature $\left(27 \pm 1{ }^{\circ} \mathrm{C}\right)$ for $18 \mathrm{~d}$. Fruit of each group was sampled for analysis at 3-day intervals of the storage life.

Measurement of weight loss rate and good fruit rate

Weight loss rate $(100 \%)=$ (Pre storage quality-Quality after storage) / (pre storage quality) $\times 100 \%$ $100 \%$

Good fruit rate $(100 \%)=($ good fruits $) /($ total fruits $) \times$

\section{Measurement of antioxidant enzyme activity}

Frozen peel tissue $(5 \mathrm{~g})$ was homogenized in $40 \mathrm{~mL}$ of $0.05 \mathrm{M}$ phosphate buffer ( $\mathrm{pH}$ 6.8) containing 6\% (w/v) PVP containing $1 \%(\mathrm{w} / \mathrm{v})$ insoluble polyvinylpyrrolidone (PVP). The homogenate was filtered through four layers of gauze removes flesh fragments. The supernatant was then centrifuged at $10,000 \times \mathrm{g}$ for $20 \mathrm{~min}$ at $4{ }^{\circ} \mathrm{C}$, and the supernatant was sampled as the crude extract for assays of 
670

SOD and POD activities. SOD activity was estimated by recording the decrease in $560 \mathrm{~nm}$ absorbance of nitro-blue tetrazolium dye (Oberley et al., 1984). POD activity was measured as described by Jung et al. (2004), using guaiacol colorimetric method to determine the change in absorbance at $470 \mathrm{~nm}$ wavelength.

For $\mathrm{H}_{2} \mathrm{O}_{2}$ determination, $4 \mathrm{~g}$ of fresh tissue was homogenized with $10 \mathrm{ml}$ of chilled $100 \%$ acetone and then centrifuged at $10,000 \times \mathrm{g}$ for $20 \mathrm{~min}$ at $4{ }^{\circ} \mathrm{C}$, the supernatant was collected immediately for $\mathrm{H}_{2} \mathrm{O}_{2}$ analysis. (Patterson et al., 1984)

\section{Measurement of MDA contents}

The MDA content was determined by the thiobarbituric acid (TBA) method (Li et al., 2010). Frozen pear meat $(0.5 \mathrm{~g})$ was homogenized in $5 \mathrm{ml}$ of $5 \%(\mathrm{w} / \mathrm{v})$ trichloroacetic acid (TCA). The homogenate was centrifuged for $10 \mathrm{~min}$ at $3,000 \times \mathrm{g}$. To $2 \mathrm{ml}$ of the supernatant was added equal amount of $0.67 \%$ thiobarbituric acid (with 5\% trichloroacetic acid preparation), The reaction solution was held for $30 \mathrm{~min}$ in a boiling water bath, cool quickly, and centrifuged at 3,000 $\times$ $\mathrm{g}$ for $10 \mathrm{~min}$. The absorbance levels of the supernatant at 450,532 , and $600 \mathrm{~nm}$ were determined. The MDA content was calculated by the following formula: $\mathrm{MDA}\left(\mu \mathrm{mol} \mathrm{L}^{-1}\right)=$ $6.45 \times\left(\mathrm{OD}_{532}-\mathrm{OD}_{600}\right)-0.56 \times \mathrm{OD}_{450}$

\section{Measurement of proline contents}

The proline content was determined by the ninhydrin method (Zhao et al., 2009). Frozen peel tissue $(0.5 \mathrm{~g})$ was extracted from $5 \mathrm{~mL}$ of $3 \%(\mathrm{w} / \mathrm{v})$ sulfosalicylic acid at 100 ${ }^{\circ} \mathrm{C}$ for $10 \mathrm{~min}$ with frequent shaking, after cooling, filter into a clean beaker. Two $\mathrm{ml}$ of the extract was sampled and added to equivalent glacial acetic acid and $2 \mathrm{~mL}$ of ninhydrin, the mixture was then boiled at $100{ }^{\circ} \mathrm{C}$ for 30 min. After cooling, the reaction mixture was extracted from $4 \mathrm{~mL}$ of toluene and the absorbance of the organic phase at $520 \mathrm{~nm}$ was determined, and the content of proline was calculated according to a standard curve.

\section{Measurement of electric conductivity}

Electric conductivity was determined as described by Feng et al. (2005). The sample was rinsed with double distilled water, and dry with filter paper moisture. Thirty skin pieces of $1 \mathrm{~cm}$ diameter and $1 \mathrm{~mm}$ thick were incubated in $100 \mathrm{~mL}$ double-distilled water for one hour. A conductivity meter was used for measurement of electric conductivity. The initial electric conductivity was measured as S1. Then heat the beaker in boiling water for $5 \mathrm{~min}$ and cooled, S2 was measured as final electric conductivity. The electric conductivity of the sample was calculated according to following equation: Electric Conductivity (\%) $=\mathrm{S} 1 / \mathrm{S} 2 \times 100 \%$.

\section{Statistical analysis}

Data were reported was mean \pm SD for triplicate determinations along with standard errors of means. Data were further subjected to analysis of variance, and means were compared using least significance difference (LSD) test (SAS Institute, Cary, USA). Statistical significance was declared at $\mathrm{P}<0.05$.

\section{Results}

Changes in weight loss rate and good fruit rate during storage

Respiration and transpiration in fruits after harvest cause them to lose water and weight, thereby affecting their appearance and quality. As shown in Fig. 1, as storage time was extended, the weight loss rate of pear fruits gradually increased because nutrients and water supplied by the pear tree and soil were lost after the fruits were harvested, leading to the natural loss of fruits because of the respiration and transpiration of fruits during storage. The increase in the weight loss rate of the control group was significantly higher than that of the treated groups during early storage stage. After 12 days, respiration and transpiration weakened, and the weight loss rate gradually decreased. During the whole storage, the weight loss rate of the treatment group was lower than that of the control group. In 6-18 days, the difference was significant. The results showed that kombucha could delay transpiration in pear fruits, reduce their weight loss rate, and prolong their delivery period.

\section{Changes in good fruit rate during storage}

The good fruit rate of storage was a key indicator used to evaluate the effect of fruit storage. The good fruit rate of the treatment group and the control group decreased with time, but the good fruit rate of the treatment grouped was higher than that of the control group (Fig. 2). In 6-18 days, the difference was significant. On the 18 th day of the treatment, the healthy fruit rate of the treatment group reached $69.44 \%$, whereas the good fruit rate of the control group was only $41.67 \%$. The effect of the pear storage on the treatment group was better than that on the control group.

\section{Changes in antioxidant enzyme activity during storage}

SOD served as a naturally occurring superoxide radical scavenging factor in the body and mainly functions in the removal of free radicals and reactive oxygen species produced by fruits and vegetables in vigorous aerobic respiration and chloroplast photosynthetic electron transfer to reduce membrane lipids.

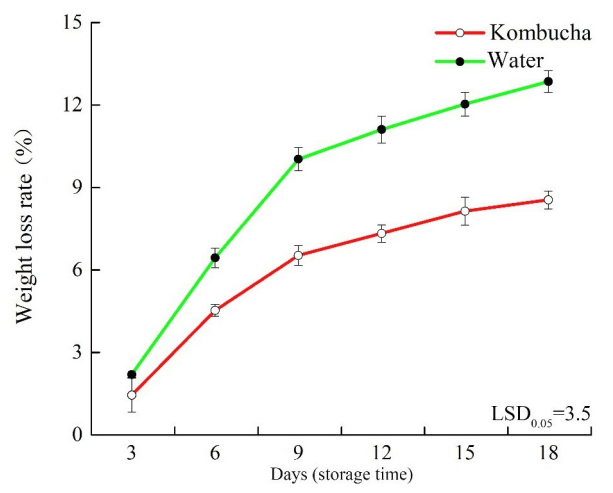

Fig. 1. The weight loss rate in the pears affected by kombucha. The green line plus the solid circle represents the water treatment, and the red line plus the hollow circle represents the kombucha treatment. The data are displayed with mean \pm SD (bars) of three replications of 6 fruits each 


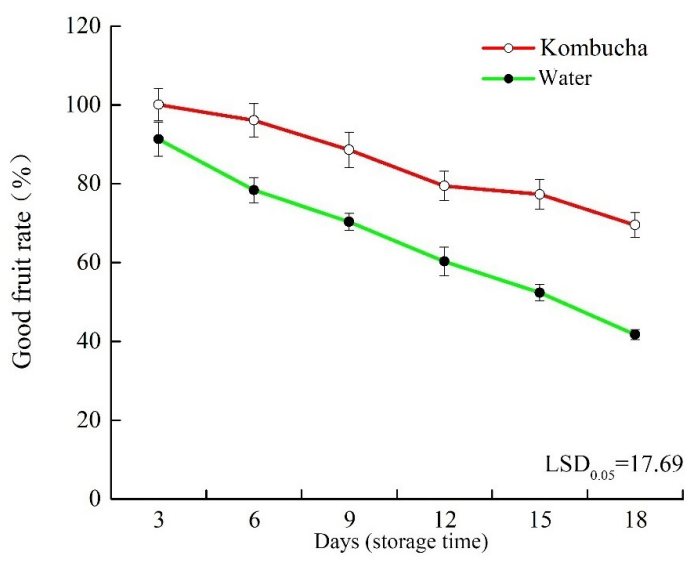

Fig. 2. The good fruit rate in the pears affected by kombucha. The green line plus the solid circle represents the water treatment, and the red line plus the hollow circle represents the kombucha treatment. The data are displayed with mean \pm SD (bars) of three replications of 6 fruits each

As shown in Fig. 3A, the SOD activity of pear fruit decreased at the early stage, increased at the middle stage, and decreased again at the later stage. The SOD activity increased slightly within 6-9 days after harvest, and the storage times was extended. After 9 days, the activity of pears gradually decreased, and the SOD activity continuously decreased. The data in each period indicated that the SOD activity of the treatment group was higher than that of the control group, and the SOD activities of the treatment group and the control group was significantly different on days 3-12. At the later stage, these activities slightly varied.

POD was a highly active oxidoreductase ubiquitous in fruits and vegetables. It was closely related to the respiration, photosynthesis, and auxin oxidation of fruits and vegetables. The POD activity of post-harvest pears initially increased and then decreased during the whole storage period (Fig. 3B). This activity further decreased after it peaked on day 15. The POD activity data of the treatment group was higher than that of the control group. This difference was significant at the early stage but was not significant after day 15. Therefore, kombucha increased the activity of fruit peroxidase.

\section{Changes in hydrogen peroxide content during storage}

Fruit aging was caused by reactive oxygen accumulation. When the accumulation of excessive hydrogen peroxide in fruits was not removed by the scavenging system, the ability of the defense system to scavenge free radicals gradually decreases during storage. As a result, $\mathrm{H}_{2} \mathrm{O}_{2}$ contents increase, $\mathrm{OH}^{-}$elicits toxic effects on fruits, and fruit senescence accelerates. As shown in Fig. 4, the $\mathrm{H}_{2} \mathrm{O}_{2}$ content of pear fruit increased in the pre-storage period and decreased after 15 days. The difference in the $\mathrm{H}_{2} \mathrm{O}_{2}$ content was significant on days 12-15. During the whole storage, the $\mathrm{H}_{2} \mathrm{O}_{2}$ content of the treatment group was lower than that the control group, possibly delaying fruit senescence.
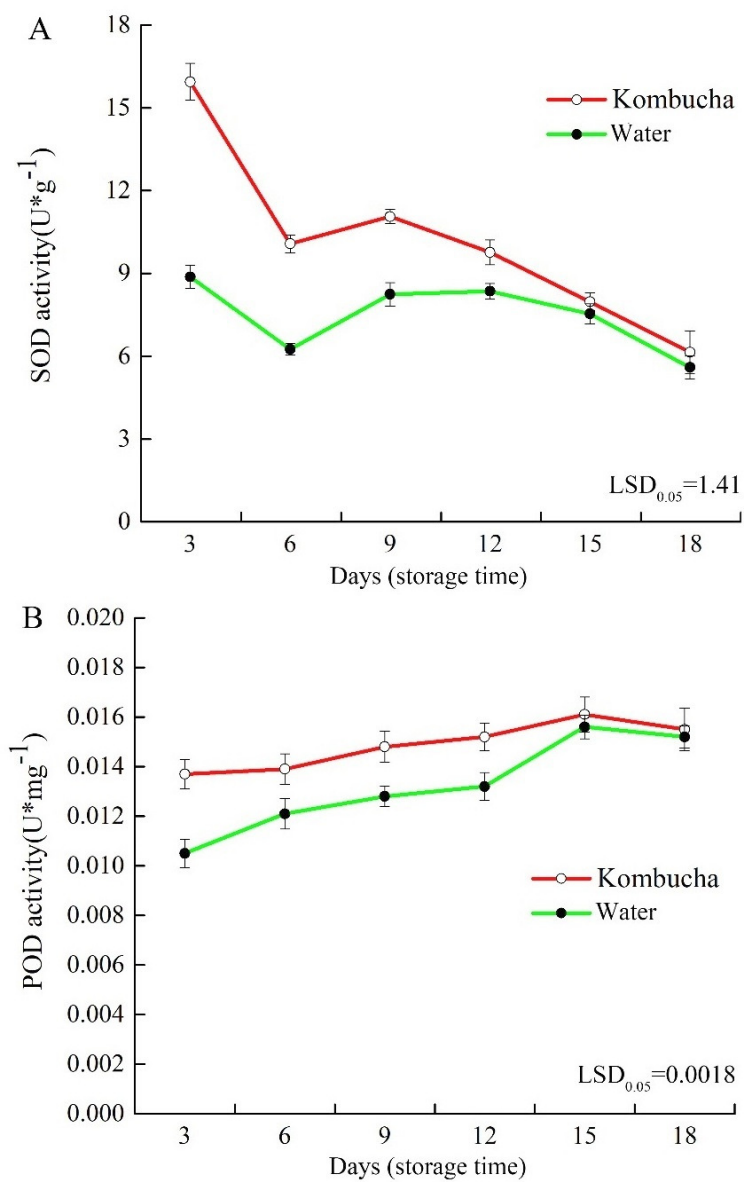

Fig. 3. The SOD (A) and POD (B) activities in the pears affected by kombucha. The green line plus the solid circle represents the water treatment, and the red line plus the hollow circle represents the kombucha treatment. The data are displayed with mean \pm SD (bars) of three replications of 6 fruits each

\section{Changes in MDA and proline during storage}

MDA was a cell membrane peroxidation product, and its content determines the degree of damage to the cell membrane. The MDA content increased during the whole storage, peaked on day 15, and decreased (Fig. 5A). The MDA content of the treatment group was lower than that of the control group. The difference between the control group and the treatment group was not significant on days 9-15. Therefore, kombucha treatment could inhibit the membrane lipid peroxidation of pear fruit cells.

Proline was an important osmotic regulator in plants, and an increase in its content was strongly related to the degree of damage to plants. As shown in Fig. 5B, the content of free proline in pear initially increased significantly and then decreased with time. This parameter showed a single peak change, peaked on day 15 , and decreased after 15 days. The proline content of the treatment group was significantly lower than that of the control group, and the difference between the two groups was significant on days 918. 
672

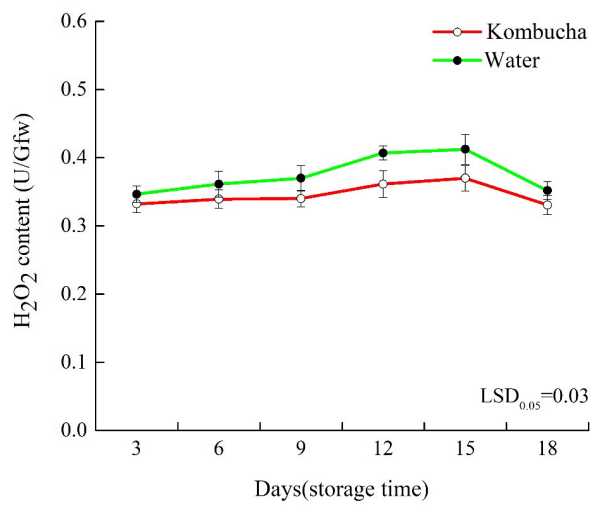

Fig. 4. The hydrogen peroxide content in the pears affected by kombucha. The green line plus the solid circle represents the water treatment, and the red line plus the hollow circle represents the kombucha treatment. The data are displayed with mean \pm SD (bars) of three replications of 6 fruits each
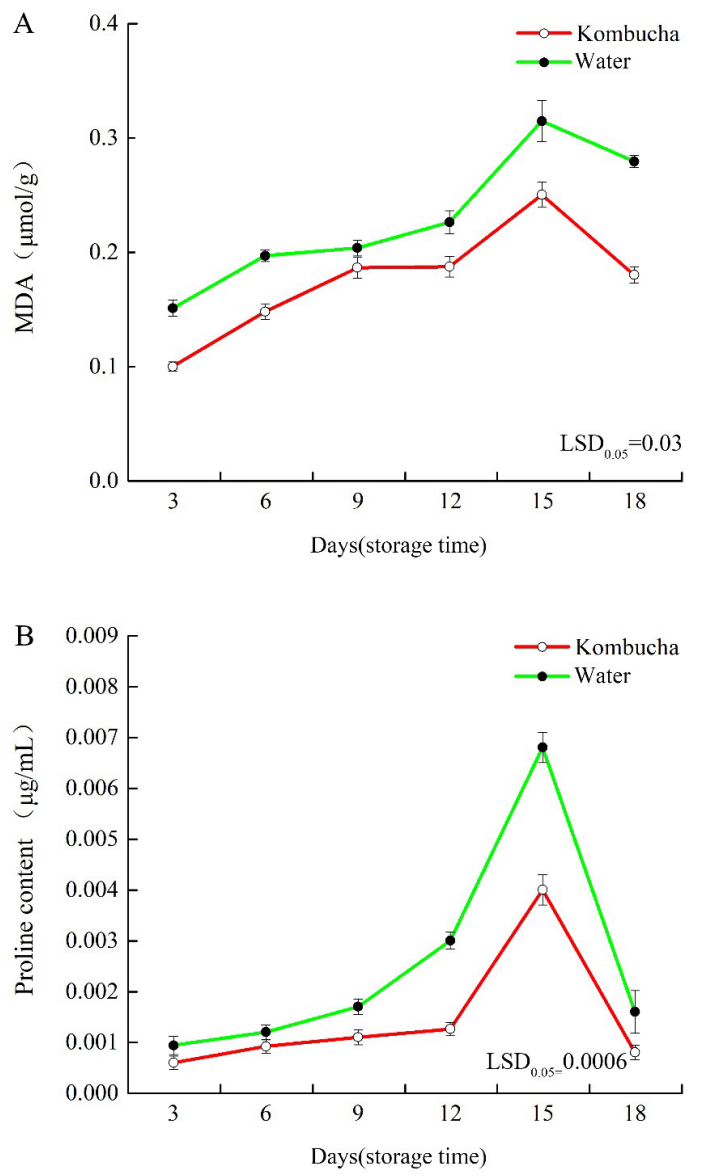

Fig. 5. The malondialdehyde (MDA) and proline contents in the pears affected by kombucha. The green line plus the solid circle represents the water treatment, and the red line plus the hollow circle represents the kombucha treatment. The data are displayed with mean \pm SD (bars) of three replications of 6 fruits each

\section{Changes in electric conductivity during storage}

Conductivity was an important indicator to reflect cell membrane permeability. The higher the cell tissue conductivity was, the greater the cell membrane permeability and the greater the damage to cell membrane integrity will be. The conductivity of pulp tissue changes as the storage time was extended. The conductivity showed a wavy fluctuation during the whole storage (Fig.6). The conductivity of the treatment group was lower and relatively more stable than that of the control group. The difference in the conductivities between the two groups was significant on days 12 and 18 .

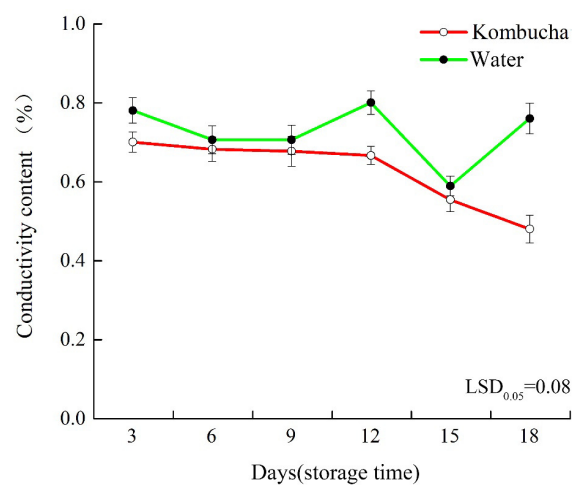

Fig. 6. The conductivity content in the pears affected by kombucha. The green line plus the solid circle represents the water treatment, and the red line plus the hollow circle represents the kombucha treatment. The data are displayed with mean \pm SD (bars) of three replications of 6 fruits each

\section{Discussion}

Abundant microbial species can produce various biologically active substances, which had an important effect on the physiological and biochemical reactions of plants and animals. Therefore, screening safe and residue-free biopreservatives had great potential. Since Gutter and Littauer (1953) reported that Bacillus subtilis have an antagonistic effect on the post-harvest pathogens of citrus fruits, researchers have extensively investigated biopreservatives. Meng et al. (2010) showed that pre-harvest spraying of antagonistic yeast combined with post-harvest chitin coating can reduce the weight loss rate of grapes during storage. Castillo et al. (2010) found that the preharvest application of Aloe vera juice can alleviate the postharvest disease of fruit, reduce the respiration and weight loss rates of fruits, delay the deepening of fruit color, and decrease the hardness of fruits. Our results confirmed that the application of kombucha treatment could maintain the quality of pear fruit during storage. After kombucha treatment was administered, the weight loss rate of the pear fruits during storage could be reduced to effectively extend their storage time. The healthy fruit rate of the treatment group was $69.44 \%$ when the fruits were stored at room temperature for 18 days, whereas the healthy fruit rate of the control group was only $41.67 \%$ when the fruits were stored for 18 days. 
The ripening and senescence of fruits are closely related to the levels of reactive oxygen metabolism and energy metabolism. In the post-harvest ripening and senescence of fruits, the accumulation of active oxygen destroys cell membrane integrity and causes cellular senescence and death (Brennan and Frenkel, 1977; Jimenez et al., 2002). In this study, kombucha treatment could inhibit the production of $\mathrm{H}_{2} \mathrm{O}_{2}$ and delay fruit senescence. The metabolic disorders of reactive oxygen can trigger free radicals in cells to produce toxic effects on biomembranes and biomacromolecules, causing structural collapse and loss of function of plant cell membrane systems ( $\mathrm{Du}$ and Bramlage, 1994). Under normal circumstances, the production and elimination of active oxygen was in equilibrium, and a low level of intracellular reactive oxygen unlikely induces damage to fruits. Once the capacity of the active oxygen scavenging system was reduced, this balance was destroyed, eventually causing fruit senescence (Ben et al., 1999). In the reaction to eliminate reactive oxygen, SOD functions as antioxidant enzyme. During storage, the SOD activity decreased, indicating that the ability of plants to eliminate active oxygen decreased and membrane lipid peroxidation increased. However, as the storage time was prolonged, the free radical content might exceed the ability of SOD to eliminate free radicals, thereby decreased the enzyme activity (Dhindsa $e t$ al., 1982). The SOD activity of pear fruit of the treatment group was higher than that of the control group, suggesting that kombucha could increase the SOD activity. POD was a highly active and adaptive enzyme widely distributed in different organelles of various plants and involved in multiple functions (Takahama and Oniki, 2000). In reactive oxygen metabolism involving POD, $\mathrm{H}_{2} \mathrm{O}_{2}$ can be decomposed into $\mathrm{O}_{2}$ and $\mathrm{H}_{2} \mathrm{O}$ to reduce the toxic effects of reactive oxygen on plants and delay the body's aging. When fruits are ageing, a decrease in the POD activity leads to a reduction in the body's ability to eliminate peroxide toxins. POD participates in different mechanisms of the ripening and storability of fruits and vegetables. At the early stage of senescence and storage, POD can increase the storability of fruits. Conversely, it reduces the storability of fruits and vegetables at the later stage of senescence and storage (Zhang and Kirkham, 1994). The results of this study indicated that the POD activity in the post-harvest pear fruit significantly peaked on day 15 . Afterward, the POD activity declined, and the fruits began to age. The treatment group was compared with the $\mathrm{H}_{2} \mathrm{O}_{2}$, SOD, and POD activities of the control group, kombucha could delay the increase in $\mathrm{H}_{2} \mathrm{O}_{2}$ contents, enhance the SOD and POD activities in pear fruit, maintain its ability to eliminate superoxide anion, and reduce the damage of reactive oxygen to biomembranes to delay fruit deterioration. This observation was consistent with that of Xu and Liu (2017) on the storage quality and antioxidant activity of blueberry after harvesting and Ippolite et al. (2000) on the change in quality index of Aureobasidium pullulans as a biological fresh-keeping agent for apple. The previous results of this group showed that the experimental results of exogenous ALA treatment of peach and chamomile showed that it could enhance the antioxidant activity of plants and delay aging, which was consistent with the treatment effect of Kombucha on pears (Ye et al., 2016; Liu et al., 2018).
Reactive oxygen can directly or indirectly initiate membrane lipid peroxidation, and MDA, the final product of membrane lipid peroxidation, can alter the structure of amino acids in proteins, thereby forming Schiff alkali, generating oxidative free radicals, and causing cell membrane structure impairment (Cao et al., 2008). The accumulation of MDA indicates the enhancement of membrane peroxidation, which can reflect the increase in cell membrane permeability and the acceleration of fruit senescence. Therefore, changes in MDA contents can correspond to the degree of lipid peroxidation in the body and indirectly indicate the degree of cell damaged. Generally, the higher the MDA contented means the more serious the degree of cell damaged in fruits $(\mathrm{Li}$ and $\mathrm{Yi}$, 2012). During the storage of pear fruit, when MDA largely accumulates, the cell membrane leaks, and membrane permeability increases, leading to electrolyte extravasation in cells and increasing cell conductivity. The change in conductivity reflects the degree of softening and rot of fruits to a certain extent. In this study, during storage, the MDA content of the treatment group was lower than that of the control group possibly because of the attachment of kombucha to the pear peel, which hindered gas exchange, reduced the degree of peroxidation, and decreased the effect on cells. The low MDA contented in the treatment group also decreased the conductivity of this group compared with that of the control group, indicating that kombucha could delay the softening and decay of the fruits and extend the storage time. Proline, as an important osmotic regulator in plants, can stabilize the metabolic processes in protoplasts and tissues and prevent cell dehydration. When plants are stressed, their proline content increases, thereby regulating intracellular osmotic potential, maintaining water balance, and protecting the enzyme activity required for intracellular metabolic activity (Wyllie et al., 1996; Cao et al., 2012). Therefore, the increase in proline content was related to the degree of damage to plants. During the whole storage, the proline content in the treatment group was lower than that in the control group, implying that fruit was less damaged in the whole storage. Therefore, kombucha could inhibit the MDA content, proline content, and conductivity, reduces the damage encountered during storage, and prolongs storage time.

\section{Conclusions}

Kombucha had a certain preservation effect on pear fruit during storage at room temperature. It can also prolong the storage time of pear fruits, delay fruit rot and softening, increase fruit storability, and delay their senescence. Biological preservatives combined with other exogenic substances have an enhanced effect. Further studies should focus on the preservation of pear fruits by combining exogenic substances and applying heat treatment.

\section{Acknowledgements}

This work was supported by the Science and Technology Development Project of Jingzhou City (2011CB36) and The Special projects for technological innovation in Hubei Province. (Grant Recipient:shuiyuan cheng) 
674

\section{References}

Abshenas J, Derakhshanfar A, Ferdosi MH, Hasanzadeh S (2012). Protective effect of kombucha tea against acetaminophen-induced hepatotoxicity in mice: a biochemical and histopathological study. Comparative Clinical Pathology21(6):1243-1248.

Aziz M, Karboune S (2018). Natural antimicrobial/antioxidant agents in meat and poultry products as well as fruits and vegetables: a review. Critical Reviews in Food Science and Nutrition 58(3):486-511.

Ben Amor, Flores B, Latche A, Bouzayen M, Pech JC, Fomojaro F (1999). Inhibition of ethylene biosynthesis by antisense ACC oxidase RNA prevents chilling injury in Charentais cantaloupe melons. Plant, Cell and Environment 22(12):1579-1586.

Brennan T, Frenkel C (1977). Involvement of hydrogen peroxide in the regulation of senescence in pear. Plant Physiology 59(3):411-416.

Cao SF, Cai YT, Yang ZF, Zheng YH (2012). MeJA induces chilling tolerance in loquat fruit by regulating proline and $\gamma$-aminobutyric acid contents. Food Chemistry 133(4):1466-1470.

Cao SF, Zheng YH, Tang SS, Wang KT (2008). Improved control of anthracnose rot in loquat fruit by a combination treatment of Pichia membranifaciens with $\mathrm{CaCl}_{2}$. International Journal of Food Microbiology 126(1-2):216-220.

CastilloS, Navarro D, Zapata PJ, Guillén F, Valero D, Serrano M, MartínezRomero D (2010). Antifungal efficacy of Aloevera in vitro and its use as a preharvest treatment to maintain postharvest table grape quality. Postharvest Biology and Technology 57(3):183-188.

Dhindsa RS, Plumb-Dhindsa PL, Reid DM (1982). Leaf senescence and lipid peroxidation: Effects of some phytohormones and scavengers of free radicals and singlet oxygen. Physiologia Plantarum 56(4):453-457.

Du Z, Bramlage WJ (1994). Superoxide dismutase activities in senescing apple fruit (Malus domestica Borkh.). Journal of Food Science 59(3):581-584.

Dufresne C, Farnworth E (2000). Tea, Kombucha, and health: a review. Food Research International 33(6):409-421.

Fan MC,LiWX, Hu XL, Sun YN, Yu G, Zhang X (2016).Effect of microvacuum storage on active oxygen metabolism, internal browning and related enzyme activities in Laiyang pear (Pyrus bretschneideri Reld). LWT-Food Science and Technology 72:467-474.

Feng GP, Yang HS, Li YF (2005). Kinetics of relative electrical conductivity and correlation with gas composition in modified atmosphere packaged bayberries (Myrica rubra Siebold and Zuccarini). LWT-Food Science and Technology 38(3):249-254.

Greenwalt CJ, Ledford RA, Steinkraus KH (1998). Determination and characterization of the antimicrobial activity of the fermented tea kombucha.LWT-Food Science and Technology31(3):291-296.

Groppa MD, Benavides MP (2008). Polyamines and abiotic stress: recent advances. Amino Acids 34(1):35-45.

Gutter Y, Littauer F (1953). Antagonistic action of Bacillus subtilis against citrus fruit pathogens. Bulletin of the Research Council of Israel 3:192196.

Holmes RA, Boston RS, Payne GA (2008). Diverse inhibitors of aflatoxin biosynthesis. Applied Microbiology and Biotechnology 78(4):559-572.

Huang CH, Yu B, Teng YW, Su J, Shu Q, Cheng ZQ, Zeng LQ (2009).
Effects of fruit bagging on coloring and related physiology, and qualities of red Chinese sand pears during fruit maturation. Scientia Horticulturae 121(2):149-158.

Ippolito A, El Ghaouth A, Wilson CL, Wisniewski M (2000). Control of postharvest decay of apple fruit by Aureobasidium pullulans and induction of defense responses. Postharvest Biology and Technology 19(3):265-272.

Itai A, Tanahashi T (2008). Inhibition of sucrose loss during cold storage in Japanese pear (Pyrus pyrifolia Nakai) by 1-MCP. Postharvest Biology and Technology 48(3):355-363.

Jimenez A, Creissen G, Kular B, Firmin J, Robinson S, Verhoeyen M, Mullineaux $P$ (2002). Changes in oxidative processes and components of the antioxidant system during tomato fruit ripening. Planta 214(5):751-758.

Jung WJ, Jin YL, Kim YC, Kim KY, Park RD, Kim TH (2004). Inoculation of Paenibacillus illinoisensis alleviates root mortality, activates of lignification-related enzymes, and induction of the isozymes in pepper plants infected by Phytophthora capsici. Biological Control 30(3):645652.

Li FJ, Zhang XH, Song BC, Li JZ, Shang ZL, Guan JF (2013). Combined effects of 1-MCP and MAP on the fruit quality of pear (Pyrus bretschneideri Reld cv. Laiyang) during cold storage. Scientia Horticulturae 164:544551.

Li G, Wan SW, Zhou J, Yang ZY, Qin P (2010). Leaf chlorophyll fluorescence, hyperspectral reflectance, pigments content, malondialdehyde and proline accumulation responses of castor bean (Ricinus communis L.) seedlings to salt stress levels. Industrial Crops and Products 31(1):13-19.

Li LH, Yi HL (2012). Effect of sulfur dioxide on ROS production, gene expression and antioxidant enzyme activity in Arabidopsis plants. Plant Physiology and Biochemistry 58:46-53.

Liu RL, Lai TF, Xu Y, Tian, SP (2013). Changes in physiology and quality of Laiyang pear in longtime storage. Scientia Horticulturae 150:31-36.

Lu HP, Lu LF, ZengLZ, Fu D, Xiang HL, Yu T, Zheng XD (2014). Effect of chitin on the antagonistic activity of Rhodosporidium paludigenum against Penicillium expansum in apple fruit. Postharvest Biology and Technology 92:9-15.

Mayser P, Fromme S, Leitzmann G, Gründer K(1995). The yeast spectrum of the 'tea fungus Kombucha' Das Hefespektrum des 'Teepilzes Kombucha'. Mycoses 38(7-8):289-295.

Meng XH, Qin GZ, Tian SP (2010). Influences of preharvest spraying Cryptococcus laurentii combined with postharvest chitosan coating on postharvest diseases and quality of table grapes in storage. LWT-Food Science and Technology 43(4):596-601.

Moon SJ, LeeSH, Han JH, Hwang YS, Chun JP (2008). Effects of 1-MCP and storage condition on fruit quality of 'Whangkeumbae' pear during storage and simulated marketing. Korean Journal of Horticultural Science \& Technology 26(4):387-392.

Oberley LW, Spitz DR (1984). Assay of superoxide dismutase activity in tumor tissue. Methods in Enzymology 105(105):457-464.

Pareek S, Yahia EM, Pareek OP, Kaushik RA (2011). Postharvest physiology and technology of Annona fruits. Food Research International 44(7):1741-1751. 
Patterson BD, Mackae EA, Ferguson IB (1984). Estimation of hydrogen peroxide in plant extracts using titanium. Analytical Biochemistry 139:487-492.

Sharma RR, Singh D, Singh R (2009). Biological control of postharvest diseases of fruits and vegetables by microbial antagonists: A review. Biological Control 50(3):205-221.

Sreeramulu G, Hu Y, Knol W (2001). Characterization of antimicrobial activity in Kombucha fermentation. Acta Biotechnologica 21(1):49-56.

Takahama U, Oniki T (2000). Flavonoids and some other phenolics as substrates of peroxidase: physiological significance of the redox reactions. Journal of Plant Research 113(3):301-309.

Wyllie SG, Leach DN, Wang YM (1996). Development of flavor attributes in the fruit of C. melo duringripening and storage. Acs Symposium 637.

Liu XM, Zhu L, Song QL, Chang J, Ye JB , Zhang WW, Xu F (2018). Effects of 5-aminolevulinic acid on the photosynthesis, antioxidant system, and $\alpha$-bisabolol content of Matricaria recutita. Notulae Botanicae Horti Agrobotanici Cluj-Napoca 46(2):418-425.

Xu FX, Liu SY (2017). Control of postharvest quality in blueberry fruit by combined 1-methylcyclopropene (1-MCP) and UV-C irradiation. Food and Bioprocess Technology 10(9):1-9.
Yan FJ, Xu SX, Chen YS, Zheng XD (2014). Effect of rhamnolipids on Rhodotorula glutinis biocontrol of Alternaria alternata infection in cherry tomato fruit. Postharvest Biology and Technology 97:32-35.

Ye JB, Yang XH, Chen QW, Xu F, Wang GY (2017). Promotive effects of 5-aminolevulinic acid on fruit quality and coloration of Prunus persica (L.) Batsch. Scientia Horticulturae 217:266-275.

Zahavi T, Cohen L, Weiss B, Schena L, Daus A, Kaplunov T, Johanan Z, Ruth B, Droby S (2000). Biological control of Botrytis, Aspergillus and Rhizopus rots on table and wine grapes in Israel. Postharvest Biology and Technology20(2):115-124.

Zhang JX, Kirkham MB (1994). Drought-stress-induced changes in activities of superoxide dismutase, catalase, and peroxidase in wheat species. Plant and Cell Physiology 35(5):785-791.

Zhao DY, Shen L, Fan B, Yu MM, Zheng Y, Lv SN, Sheng JP (2009). Ethylene and cold participate in the regulation of LeCBFI gene expression in postharvest tomato fruits. FEBS Letters 583(20):33293334 . 